C COMMUNICATION

Volume 8 Issue 12016

DOI: 10.5959/eimj.v8i1.402

ARTICLE INF0

Submitted: $30-10-2015$

Accepted: 10-03-2016

\section{Breaking Bad News Workshop as Peer-Assisted Learning Project in Primary Care Clerkship}

\author{
Nur Faraheen Abdul Rahman, Muhammad Ibrahim Azmi \\ International Medical School, Management and Science University, \\ Malaysia
}

\begin{abstract}
Breaking bad news is a crucial communication delivered by healthcare professionals. This skill was taught in Management and Science University, Malaysia using lecture previously. Realising the instructional delivery gap, breaking bad news workshops was introduced involving not only the theory of the skills but the hands on experience as well. This workshop incorporated peer-assisted learning method in providing a friendly and conducive environment for the best learning experience for the students. Five workshops were conducted with a total of 204 students. Students ( $n=38-42$ per session) were given materials a week prior to the session to familiarise themselves with the workshop. Trained peer-assisted tutors $(n=8)$ guided role-playing sessions as well as giving feedbacks. Students found that the workshop to be useful adjunct to learning communication skills, specifically in breaking bad news. Students considered peer-assisted learning method provided them with a safe environment where mistakes were allowed, corrected and proper skills reiterated. In conclusion, learning breaking bad news is feasible with peer-assistance.
\end{abstract}

Keywords: Peer-assisted learning, Breaking bad news, Challenging communication, Communication skills, Experiential learning, Medical education

CORRESPONDING AUTHOR Nur Faraheen Abdul Rahman, International Medical School, Management and Science University, University Drive off Persiaran Olahraga, Section 13, 40100 Shah Alam, Selangor, Malaysia | Email: nur_faraheen@msu.edu.my

\section{Introduction}

Breaking bad news is categorised as challenging communications and is taught during year 4 Primary Care posting in the Management and Science University, Malaysia. Prior to this, breaking bad news was taught as a lecture. Realising that breaking bad news contained not only cognitive but also demonstrable skills and attitude domains, we have reviewed the instructional delivery to make it more encompassing and "handson". This workshop was based on social constructivism learning theory, in that it emphasised collaboration between individuals within a group in a learning process each coming in with some form of prior knowledge (1). The workshop used experiential learning methodology by means of role-playing as its main mode of instructions. Final year undergraduate students contributed to the workshops as a peer-assisted learning project. Peer assisted learning is proven to be beneficial to medical students but is often underutilised $(2,3,4,5)$. Research has shown that students' achievements tutored by peers are not at a disadvantage compared to facultytutored (6) and students preferred peertutors, as it provided safe-environment to make mistake without being penalised (2, 5). The workshop had dual aims which firstly to demonstrate on how to break bad news to simulated patients and secondly to give opportunities for students to experience peer-assisted learning. The purpose of this paper is to document the experience of running breaking bad news workshops using peer-assisted learning and its immediate 
outcomes based on students and peer-tutors feedbacks.

\section{Method}

We conducted five workshops for a total of 204 undergraduate primary care clerkship students. The workshop begun with a plenary session focusing on its aims and content based on topical reading materials given prior to the session. Students ( $\mathrm{n}=$ 38-42 per session) were also given casescenarios complete with relevant references to prepare before the workshop. Cases used were variable and were mapped against students' program educational outcomes. Students were divided into four groups and each group will have one or two peertutors $(\mathrm{n}=8)$ who played the patients while peer-students role-played as doctors (7). Peer-tutors were trained twice before the workshop began and once prior to each subsequent session as a refresher on two main aspects: how to be simulated patients and on giving constructive feedback. Students were also asked to reflect on individual and peer performance, including their strengths, weaknesses and what they wished to learn further (learning plan). Peer feedback was also sought from fellow group members as well as from the peer tutors. In addition, feedback was also given to each peer-tutor during debriefing session. Evaluation for this workshop was done using course evaluation survey. Students gave verbal feedback as well as in a form of free written texts, whilst peer tutors collectively wrote a report after each session.

\section{Result}

\section{Students' Remarks}

Among the comments were that the workshops generated opportunities for students to practice challenging communications. Students enjoyed the workshop and requested more training sessions for similar purposes. Students also registered their interests to be future peertutors. Students remarked that learning communication skills using simulated patients should be taught earlier in the preclinical years.

\section{Strengths of the Project}

As a team, we thought that the strengths of this project were that this module was designed based on the literatures of teaching and learning challenging communication skills. Assistance from the senior students as peer tutors was also the anchor to this project. Peer-tutors found that by teaching the juniors, their skills, knowledge and attitude towards breaking bad news were better especially with feedback from the teacher (and peers) about their performances, in addition to their understanding of the different cases used as the scenarios for role-plays.

\section{Limitations of the Project}

The limitations were that we used the same pool of dedicated senior students because there was limited resource to train other interested students. Mapping of peertutors' availability for each session was also challenging as they juggled with their own study requirements. Year 4 students entered the workshop at times unprepared and this impeded on their learning experience.

\section{Going Forward}

On the other hand, students who came prepared for the session found the learning tasks easier to handle and master. We hoped to design future workshops better by expanding the numbers of peer-tutors, reviewing the teaching materials and setting up case scenarios bank. This workshop also needed better tool to evaluate its outcomes including examining its effect on the transfer of learning which can be done by formal clinical examination's performance on breaking bad news. 


\section{Discussion}

The experiential learning theory explained about learning through experience. Kolb's experiential learning theory stated that students learn deeply with experiences. It is based on the constructivist approach of learning where knowledge, skills and attitude are continuously formed and reformed over a passage of time. It is also related to the situated learning theory that emphasised transfer of knowledge to be the greatest when learning is done within a setting where the knowledge is applied (8). This workshop supported the notion that peer-assisted learning is useful in medical education (2, 3, 4, 5). Benefits to our students included the opportunity for them to experience different ways of learning breaking bad news within a safe environment. Feedback giving and receiving were also emphasised in peerassisted learning. On the other hand, it helped the peer-tutors understood the curriculum content (7). Peer-assisted learning encouraged meta-learning (thinking about learning) where peer tutors reflect upon their own learning needs. In addition, peer-assisted learning equipped peer tutors with teaching skills, while at the same time enhanced facilitator skills (9) previously identified as important competency for future doctors (5). Hence, from this workshop, it was clear that teaching breaking bad news using peer-assisted learning is feasible. Future study should focus on the tangible impact of such initiative in the form of students' performance when breaking bad news.

\section{Conclusion}

Learning breaking bad news could be taught using peer-assisted learning. Students felt the workshop was appropriate to be used as an instructional model for teaching challenging communication. It helped to boost the confidence of peer-tutors besides consolidating their own knowledge, skills and attitude on the same topic.

\section{References}

1. Zhao C, Kuh G. Adding value: learning communities and student engagement. Research in Higher Education. 2004;45(2):115-138.

2. Ross MT, Cumming, AD. Peer-assisted learning. In: Dent JA, Harden RM, editors. A practical guide for medical teachers. London, England: Churchill Livingstone Elsevier; 2013, p. 134-141.

3. Field M, Burke J, McAllister D, Lloyd D. Peer-assisted learning: a novel approach to clinical skills learning for medical students. Medical Education. 2007;41(4):411-418.

4. Ross M, Cameron H. Peer assisted learning: a planning and implementation framework: AMEE Guide no. 30. Medical Teacher. 2007;29(6):527-545.

5. Nelson A, Nelson S, Linn A, Raw L, Kildea $\mathrm{H}$, Tonkin A. Tomorrow's educators ... today? Implementing near-peer teaching for medical students. Medical Teacher. 2013;35(2):156-159.

6. Furmedge D, Iwata K, Gill D. Peerassisted learning - beyond teaching: how can medical students contribute to the undergraduate curriculum? Medical Teacher. 2014;36(9):812-817.

7. Mavis B, Turner J, Lovell K, Wagner D. Faculty, students and actors as standardized patients: expanding opportunities for students' assessments. Teaching and Learning in Medicine. 2006;18:130-136.

8. Yardley S, Teunissen PW, Dornan T. Experiential learning AMEE guide no. 63. Medical Teacher. 2012;e102-115.

9. Kam JK, Tai J, Mitchell RD, Halley E, Vance S. A vertical study programme for medical students: peer-assisted learning in practice. Medical Teacher. 2013;35(2), e943-e945. 